\title{
Potential explanations for increasing methylphenidate use in children and adolescents with attention-deficit/hyperactivity disorder in Germany from 2004 to 2013 \\ Ingo Langner, Ulrike Haug, Oliver Scholle, Christina Lindemann, Carsten Schröder, Oliver Riedel
}

\section{DOI}

10.1097/Jcp.0000000000000980

\section{Published in}

Journal of Clinical Psychopharmacology

\section{Document version}

Accepted manuscript

This is the author's final accepted version. There may be differences between this version and the published version. You are advised to consult the publisher's version if you wish to cite from it.

\section{Online publication date}

30 November 2018

\section{Corresponding author}

Ingo Langer

\section{Citation}

Langner I, Haug U, Scholle O, Lindemann C, Schröder C, Riedel O. Potential explanations for increasing methylphenidate use in children and adolescents with attentiondeficit/hyperactivity disorder in Germany from 2004 to 2013. J Clin Psychopharmacol. 2019;39(1):39-45.

This is a non-final version of an article published in final form in the Journal of Clinical Psychopharmacology. 


\section{TITLE PAGE}

Title: $\quad$ Potential explanations for increasing methylphenidate use in children and adolescents with Attention-Deficit/Hyperactivity Disorder in Germany from 2004 to 2013

Authors: $\quad$ Ingo Langner ${ }^{1}, \mathrm{PhD}$; Ulrike Haug ${ }^{1}, \mathrm{PhD}$; Oliver Scholle ${ }^{1}, \mathrm{MSc}$; Christina Lindemann ${ }^{1,2,3}$, MSc; Carsten Schröder ${ }^{1}$, PhD; Oliver Riedel ${ }^{1}$, PhD;

Affiliations: $\quad{ }^{1}$ Department: Clinical Epidemiology, Leibniz Institute for Prevention Research and Epidemiology - BIPS, Bremen

${ }^{2}$ Medical School Hannover, Hannover

${ }^{3}$ Centre for Interdisciplinary Addiction Research, University Medical Center HamburgEppendorf, Hamburg

Corresponding author: Ingo Langner, Leibniz Institute for Prevention Research and Epidemiology BIPS, Achterstraße 30, 28359 Bremen, GERMANY

ORCID: 0000-0001-8998-1236

E-mail: langner@leibniz-bips.de

Tel.: $\quad+49(0) 421218-56862$

Fax: $\quad+49(0) 421218-56941$

\section{Acknowledgments}

We would like to thank the AOK Bremen/Bremerhaven, the DAK - Gesundheit, the hkk Krankenkasse, and the Techniker Krankenkasse (TK) who provided the data for this study. 


\section{Conflicts of Interest and Source of Funding}

Ulrike Haug, Oliver Riedel, Oliver Scholle, Carsten Schröder, and Ingo Langner are working and Christina Lindemann formerly at the Leibniz Institute for Prevention Research and Epidemiology BIPS. BIPS occasionally conducts studies financed by the pharmaceutical industry. Almost exclusively, these are post-authorization safety studies (PASS) requested by health authorities. The studies and the resulting publications are not influenced by the pharmaceutical industry. The present work is unrelated to the above grants and relationships. The authors declare that they have no further conflicts of interest.

There was no external support from any grant or funding source for this study. There are no commercial interests. This study was funded by the Leibniz Institute for Prevention Research and Epidemiology - BIPS.

Running title

Methylphenidate use in minors

\section{Authors' Contributions}

IL, OS and OR conceived the study and planned the design. IL, OL and UH obtained the permission from SHIs and administrative authorities to use the claims data for this study. IL performed the statistical analyses. IL, CL, CS and OL wrote the first draft of the manuscript. UH, OS, and OR provided supervision and critical review of the manuscript. All authors contributed to and have approved the final manuscript. 


\section{Abstract}

Purpose/Background: Despite a decreasing population of children and adolescents, the cumulative total amount of dispensed methylphenidate (MPH), the first-choice treatment of attentiondeficit/hyperactivity disorder (ADHD) in this age group, has increased dramatically in Germany. We investigated potential reasons for this increase like changes in the ADHD prevalence over time and other potential explanations including the cumulative amount of dispensed MPH per person.

Methods/Procedures: Based on German claims data, we calculated standardised annual ADHD prevalence rates, proportions of ADHD cases treated with MPH and/or psychotherapy and mean cumulative defined daily doses (DDDs) of ADHD drugs for 3- to 17-year-old children and adolescents from 2004 to 2013.

Findings/Results: The ADHD prevalence increased continuously from 2004 to 2011 and remained stable thereafter. In ADHD cases, there was little variation in the proportion of individuals treated with drugs and in the frequency of psychotherapeutic treatment during the whole study period. The annual cumulative mean amount of MPH DDDs increased by about 30\% from 2004 to 2008 .

Implications/Conclusions: Our analyses suggest that the increase in MPH use in Germany was mainly influenced by an increasing ADHD prevalence and increasing amounts of dispensed MPH per person.

\section{Keywords}

Attention-deficit/hyperactivity disorder (ADHD), prevalence, treatment, methylphenidate, psychotherapy. 


\section{Introduction}

Methylphenidate (MPH) is an important pillar in the medical treatment of attentiondeficit/hyperactivity disorder (ADHD) in children and adolescents. In several countries, prescriptions for MPH increased substantially during the past decade [1-7]. In Germany, the cumulative absolute number of defined daily doses (DDDs) of MPH dispensed for children and adolescents increased by 168\% between 2003 and 2008 and has remained at this high level since 2009 [1, 8], despite a decrease of the population of 3-17-year-olds (i. e. the typical age range in which ADHD is usually initially diagnosed) by $10 \%$ between 2004 and 2013 [9]. However, most studies described such increments on a population level without investigating the underlying reasons on the individual level. In fact, increased MPH utilizations may not necessarily be caused by increased ADHD prevalence alone. Actually, there are five potential explanations for increased MPH dispensations, including 1) a simple overall increase in ADHD prevalence [10]; 2) a cohort effect resulting from raised awareness of ADHD in combination of ADHD at the age of 9 years [11] followed by an expansion of the age range with higher prevalence rates or resulting from longer drug treatments of ADHD cases; 3) and increase of MPH treated patients among ADHD cases, 4) an increase of MPH dispensations per ADHD patient; 5) An increase of MPH utilisations due to decreases of alternative treatment options (e.g. other drugs like atomoxetine or psychotherapy) [6]. Each of these reasons could cause by itself an increase of MPH prescriptions on the population level. However, the calculated ADHD disease and treatment prevalence rates are also influenced by the age and sex distribution of the examined population of children and adolescents as ADHD prevalence and drug treatment regimes strongly vary with age and sex $[11,12]$. So far, to our best knowledge, no study has investigated the role of the potential explanations listed above, independent of age and sex, and focussing on ADHD prevalence, MPH utilisations and alternative treatment options in total as well as relative to the number of ADHD cases. 
We therefore aimed to investigate the above-mentioned influences on the increase in dispensed MPH among children and adolescents with ADHD disentangled from the possible effects of a changing age distribution in this population, using a large German claims database.

\section{Materials and Methods}

\section{Data source}

We used the German Pharmacoepidemiological Research Database (GePaRD) which includes claims data from four SHIs with information on about 20 million persons from all over Germany as described elsewhere [13-15]. In brief, for each included subject, GePaRD contains demographic data such as age, sex and residence as well as information on in- and outpatient diagnoses and treatment. Diagnoses are coded according to the German modification of the International Classification of Diseases version 10 (ICD-10-GM) and codes for outpatient procedures follow the German fee schedule (so-called "Einheitlicher Bewertungsmaßstab", EBM).

\section{Study population and identification of ADHD cases}

For each calendar year from 2004 to 2013, we selected a separate study population. Included subjects had to be insured for a continuous period of at least 365 days beginning in the respective analysed calendar year and they had to be aged between 3 and 17 years in that year.

Then, we identified ADHD cases based on diagnosis codes and dispensed drugs specific to ADHD treatment according to an algorithm explained elsewhere $[11,13]$. In brief, case definition was based on ADHD diagnoses from the inpatient or outpatient care sector, the latter of which requiring reconfirmation to increase validity. Thus, individuals were classified as ADHD cases, if they had I) at least one inpatient diagnosis for a hyperkinetic disorder (ICD-10 codes F90.0 or F90.1), or II) an corresponding outpatient diagnosis (F90.0 or F90.1) followed by at least another outpatient diagnosis (F90.0, F90.1 or F90.9) in at least one of the following three calendar quarters or from a different doctor in the same quarter or III) a F90.0 or F90.1 diagnosis and an MPH (ATC-code: N06BA04) or 
atomoxetine (ATX; ATC-code: N06BA09) prescription dispensed within a period of 365 days. We assigned an index date to each ADHD case using the date of the first event (diagnosis or prescription) considered for case identification. Due to the focus of this manuscript, psychotherapy was not considered for case identification.

\section{Identification of treatment among ADHD cases}

In Germany, MPH and ATX can only be dispensed in pharmacies upon prescription from a physician. Such dispensations are covered by SHIs and are therefore documented in claims data. In Germany, MPH was approved for children and adolescents during the total study period while ATX received approval for this age group in 2005.

Starting with the index date of the ADHD case, each subject was followed for 365 days. ADHD cases with any dispensed prescription of MPH or ATX (which are the most frequently used drugs in ADHD therapy in Germany [1]) during this period were classified as treated with ADHD drugs. Based on conventional DDD values and information on the amount of active component included in a single drug package, both provided by the scientific institute of the 'Allgemeine Ortskrankenkassen' (WIdO), for each single record of dispensed prescriptions the number of DDDs dispensed were calculated (one DDD represents the mean individual daily dose proposed by therapy guidelines). Lisdexamphetamine and dexamphetamine were not considered in this study. In Germany, the former was only approved in 2013 and the latter is rarely used [16].

To identify psychotherapeutic treatment among ADHD cases, we used fee schedule items (EBMcodes) specific to behaviour therapy with a treatment date in the respective period. These items included short- and long-term individual and (small) group therapy for which approval from SHIs is required (see Table with EBM-codes in Supplemental Digital Content_1).

\section{Statistical analyses}


We calculated ADHD prevalence rates per calendar year by dividing the number of identified ADHD cases with an index date in that year by the number of persons who were continuously insured from the $1^{\text {st }}$ of July of that year until the $30^{\text {th }}$ of June of the following year. The latter correlates with the so-called 'midyear population' in which each of the included subjects had a continuous insurance period of at least one year. First, we calculated crude 1-year prevalence rates for each calendar year stratified by sex, age (one-year age classes), and federal state. Second, we calculated standardised prevalence rates for each calendar year using the German population figures of 2006 derived from the German Federal Statistical Office as reference. As described in detail in the Supplement (see text in Supplemental Digital Content_2), standardisation took into account sex, age, and federal state. We used the same methods to calculate standardised proportions of ADHD cases under treatment based on the age distribution of ADHD cases in 2006 for each calendar year.

For standardised rates and proportions, we calculated 95\% confidence intervals (CI) [17].

On the individual level, we calculated cumulative amounts of DDDs prescribed within 365 days after the index date. Separately for MPH and ATX, the DDDs of all respective dispensed prescriptions in this period were summed up. Based on these individual cumulative DDDs, we calculated ageweighted means for MPH and ATX for the age group 5 to 17 years and corresponding $95 \% \mathrm{Cl}$ for each calendar year stratified by sex (for details see text in Supplemental Digital Content_3).

All statistical analyses were conducted using SAS Version 9.3.

\section{Results}

\section{Study population}

From 2004 to 2013, a total of $17,571,290$ subjects were included in our analyses $(9,004,505$ males, $8,566,785$ females). The annual sample size varied between 1,564,677 subjects in 2004 and 1,852,056 subjects in 2013 (for details see Table in Supplemental Digital Content_4 with figures for each year) and about $18 \%$ of all included individuals were younger than 6 years. 


\section{ADHD prevalence}

For the study years 2004 to 2013, the standardised ADHD prevalence rates of the study population are depicted in Figure 1 (corresponding values are tabled in Supplemental Digital Content_5). The rates increased continuously from 2004 to 2011 and showed only slightly varying values from 2011 to 2013. From 2004 to 2011 , the prevalence increased by $69 \%$ from $33.9 / 1,000$ (95\% Cl: $33.5-34.3$ ) to 57.2/1,000 (95\% Cl: 56.7-57.7) among males and by $107 \%$ from $8.6 / 1,000$ (95\% Cl: $8.4-8.9)$ to 17.8/1,000 (95\% Cl: 17.5-18.1) among females.

The crude age-stratified prevalence rates increased annually in almost all 1-year age bands from 2004 to 2010 (see Figure in Supplemental Digital Content_6). Contrarily, in the following years, increases occurred only in the age groups 12 years or older and were less pronounced. A mere cohort effect, which would have led to a widening of the curve of the age-specific prevalence rates over the years, was not found.

\section{Proportion of treated ADHD cases}

Among ADHD cases, the annual standardised proportion with MPH or ATX drug treatment varied between $50.5 \%$ and $61.8 \%$ for males and between $41.5 \%$ and $55.4 \%$ for females from 2004 to 2013 (see Figure 2; corresponding values are tabled in Supplemental Digital Content_5). Proportions varied in time with alternating directions during the observed period. A maximum was reached in 2006/2007. After that, proportions slowly decreased until 2013 and already dropped below the values of $2004 / 2005$ in 2011 . This was similar for both sexes. Only a small proportion of all ADHD cases had both drug and psychotherapeutic treatment (see Figure 3; corresponding values are tabled in Supplemental Digital Content_5). From 2004 to 2013, this proportion slightly increased from 2.65\% (95\% Cl $2.41 \%-2.91 \%)$ to $3.76 \%(95 \% \mathrm{Cl} 3.47 \%-4.07 \%)$ for males and from $2.61 \%$ (95\% Cl $1.83 \%$ $3.54 \%)$ to $3.49 \%(95 \% \mathrm{Cl} 2.86 \%-4.17 \%)$ for females. An even smaller proportion of all ADHD cases received behavioural treatment without any MPH or ATX treatment (see Figure 3; corresponding values are tabled in Supplemental Digital Content_5): from 2004 to 2009, this proportion varied only 
slightly for males between $1.45 \%(95 \% \mathrm{Cl} 1.27 \%-1.63 \%)$ and $1.61 \%(95 \% \mathrm{Cl} 1.42 \%-1.81 \%)$ and for females between $1.71 \%(95 \% \mathrm{Cl} 1.29 \%-2.20 \%)$ and $2.04 \%(95 \% \mathrm{Cl} 1.64 \%-2.48 \%)$ while in the following 3 years, especially for males, this proportion increased reaching $2.75 \%$ (95\% Cl $2.47 \%-3.05 \%$ ) for males and $2.80 \%$ (95\% Cl 2.39\%-3.24\%) for females in 2013.

\section{Prescribed DDD per drug-treated ADHD case}

The mean cumulative amount of MPH DDDs prescribed during one year for MPH-treated ADHD cases was lower for females than for males (see Figure 4). The temporal trend of the mean cumulative DDDs was similar for both. For MPH, the values increased from 2004 to 2008, remained nearly unchanged until 2012 and then slightly decreased in 2013. This pattern was similar for all 1-year age bands (see Figure in Supplemental Digital Content_7). For ATX, the values increased only from 2004 to 2006 and showed hardly any change afterwards.

\section{Discussion}

This study is among the first to investigate several factors possibly determining the increase in dispensed MPH prescriptions in Germany during the past decade and disentangled these influences from the effects of a changing age distribution among the population of prevalent ADHD cases. We identified an increase in the ADHD prevalence and higher amounts of prescribed MPH per drugtreated ADHD case as the main triggering factors.

MPH is the most frequently used first-line treatment option for ADHD cases in children and adolescents in Germany. In Germany, the population aged 3-17 years declined between 2004 and 2013 in Germany due to years with decreasing birth rates between 2000 and 2010 [18].Beside this decline, these ageing cohorts with a low birth rate also changed the age distribution of the population aged 3-17 years during the study period by subsequently reducing the proportion of lower age groups. Thus, one might have expected a decrease in the total amount of prescribed ADHD drugs recorded in claims data. The opposite, a substantial increase, occurred. Therefore, rather 
influential factors must have counteracted the effect of the decreasing population. We proposed five potential mechanisms each of which could have resulted in an increase of dispensed MPH. We explored these potential influences independently of the demographic development of the whole population and the population of ADHD cases by calculating standardised estimates.

First, an increasing prevalence of diagnosed ADHD could have increased the number of potential MPH users and therefore the amount of prescribed MPH. In the present claims data-based study, the overall diagnosis-based ADHD prevalence estimates increased starting in 2004 and reached a plateau in 2011. Importantly, the overall prevalence rates increased by $65 \%$ and more than doubled in females during the same time. As we used age-standardized estimates this reflects a true disease prevalence increase independent from possible effects of a changing age distribution in the population. The prevalence increase is in line with other German claims data-based studies for the years 2006-2011 [19] and 2006-2013 [20].

Second, ADHD prevalence and incidence rates in Germany have been described to reach a maximum at the age of 9-10 years in 2005/2006 [11]. Due to the chronic character of ADHD, one would expect a widening of the prevalence maximum towards older ages over the years [11]. This would increase the total ADHD prevalence over the years and consequently the total amount of consumed ADHD drugs [10]. We found no clear indications for this potential influence on the increase of dispensed MPH. However, such an effect could have been masked by the prevalence increase in all individual age groups. In this context, it should also be noted that in other countries rapid expansions of psychiatric diagnoses in youth were reported to be associated with more rapid increases of "mild", "subthreshold" and "NOS" diagnoses [21, 22]. However, this explanation can be ruled out as a contributing factor in our study, which on the one hand was based on claims data and ICD-10 diagnoses which do not allow to code different severity of ADHD explicitly (see also below the 
discussion of administrative prevalence as a potential limitation) and on the other hand used a ADHD case definition that required at least one specific diagnostic code of "hyperkinetic disorders" $[11,13]$.

Third, an increase in the proportion of drug-treated ADHD cases among all ADHD cases could have increased the amount of dispensed MPH. We showed that variations in the proportion of patients treated with either MPH or ATX were only small from 2004 to 2013. Considering the population decline in the age group 3-17 years, this should have decreased rather than increased the total amount of dispensed MPH in Germany. Another claims data analysis for 2006-2013 [20] found a time trend of the proportion of drug-treated ADHD cases similar to our results while the absolute values for their proportions were considerably lower. Contrary to our approach, the authors analysed the data only per individual year. Therefore, only prescriptions in the same calendar year as the diagnosis were considered for each ADHD case. This could have led to an underestimation of the proportion of drug-treated cases if treatment start was delayed to the time of the diagnosis or if updating the diagnosis was inconsistent. Based on claims data, Abbas et al. [23] presented prevalence rates for the use of stimulating drugs showing increasing values from 2004 to 2009. However, in the corresponding calculations, all insured subjects were used as the reference population, while we considered all ADHD cases as reference population.

Fourth, an increase in the amount of MPH prescribed per individual could have increased the amount of MPH dispensed in total. Our results showed that the mean amount of MPH DDDs prescribed per drug-treated ADHD case increased by about 31\% from 2004 to 2008 and remained nearly unchanged thereafter. This pattern might have been partially due to the decision of the 'The Federal Joint Committee (G-BA)' in 2009 to restrict stimulant therapy for children and adolescents. In brief, stimulants for minors with ADHD should only be prescribed within a therapeutic regimen and by specialised psychiatrists and psychotherapists $[24,25]$. 
Fifth, a variation in the frequency of applied treatment options alternative or complementary to MPH drug treatment such as behaviour therapy might have influenced the amount of dispensed MPH. However, the proportion of ADHD cases with behaviour therapy was low, with less than $4 \%$ with additional psychotherapeutic treatment and less than $2 \%$ with psychotherapy alone. It seems unlikely that changes in the frequency of psychotherapeutic treatment played more than a minor role in the variations of the proportion of drug-treated ADHD cases. The slight decrease of the proportion of ADHD cases treated with MPH or ATX after 2006 was not accompanied by a corresponding increase in psychotherapies. Also ATX could have been used alternatively to MPH, but, as also shown in our data, the dispensed annual cumulative DDDs for ATX were much lower than for MPH and changed only marginally during the study period [8].

A trend of an increasing number of patients with prescriptions for MPH during the last decade was observed in several countries $[1-7,20,26,27]$. However, the identification of reasons for this increasing treatment prevalence was restricted in most of these studies either due to the calculation based on the total population instead of ADHD cases or due to not taking into account potential variations in the age distribution or both. As an exception, Roick and Waltersbacher [20] presented for the age group of 6-17 years in Germany claims data-based annual prescription rates of ADHD drugs for 2006 to 2013 that were age-standardised with the German population and that referred to the annual population of ADHD cases. However, they provided no $\mathrm{Cl}$ for their prevalence estimates and did not consider potential variations in the age distribution of the population of ADHD cases. Steinhausen and Bisgaard [7] used a different approach. In addition to an age standardisation based on the total population, they adjusted for the annual number of patients attending mental health services in their calculation of prevalence rates for stimulant drug prescriptions which could indirectly consider as a proxy the potentially varying prevalence of diagnosed ADHD over time. In Europe, a recently published Spanish study based on pharmacy dispensing data from 2010-2014 also identified an increase of MPH prescriptions during the observation period, with higher treatment 
rates of male patients as well [28]. They confirm the results from an earlier published study from the UK primary care sector, which was also based on a large health care database, and which also detected a significant increase in prescriptions from 2003 to 2008 [29]. Similar findings were also obtained outside Europe, e. g. Taiwan [30]. Although the estimated prevalence figures from these studies are difficult to compare with our findings due to - as already discussed - differences of age ranges and years under study or due to the choice of total populations as denominator, it can be considered a strong indicator for the validity of our own findings, that prescription increases apparently can be observed worldwide. Based on additional assumptions, some studies discussed possible reasons for the increasing treatments with ADHD drugs on the population level. For example, the increased public and clinician awareness about the symptoms and associated impairments of $\operatorname{ADHD}[1,6,26,27,31]$ may have led to an increase in medicated ADHD patients and/or in the individual duration of pharmacological ADHD treatment $[6,23,32]$. This would correspond to the cohort effect in our study. More recently, the trend of treatment rates with ADHD drugs on the population level in some European countries showed a plateau $[1,23,32]$. Possible reasons discussed for this stagnation are changes in product labelling recommended by a European Medicines Agency committee [33] as well as prescription restrictions for MPH products by the German regulatory agency [24], a more cautious stance toward pharmacotherapy among physicians and parents due to these restrictions or simply a sufficient medication supply for ADHD patients in need of treatment $[1,23,32]$. Otherwise, the decrease in the proportion of drug treated ADHD cases after 2009 shown in our study might have been initiated by the warnings concerning potential cardiovascular risks of ADHD medications [34]. However, it is not clear to which extent the trend patterns used for the lines of argument were influenced by changes in the age distribution of the total population or the population of ADHD cases.

Based on claims data from several SHIs, this study population covered all geographical regions in Germany and the data source has been shown to be representative for Germany [35, 36]. In addition 
to the size of GePaRD, the main strength of the present analyses is that data on ADHD diagnoses and treatments were available both on the individual level and in one data source. As case identification and treatment were based on routinely recorded physician diagnoses and prescriptions, recall bias can be ruled out. The use of a three quarter follow-up additionally increased the validity of outpatient diagnoses. It remains unclear, whether a longer follow-up would have further contributed to validity, yet it should be noted that longer follow-up periods would have limited the number of available data years, in which ADHD cases could have been identified. Based on our longstanding experiences in case validation in health claims data $[11,13]$ and the diagnostic criteria for ADHD which require the presence of relevant symptoms for at least 6 months, the choice of 3 quarters can be regarded a reasonable compromise. By using the 12-month prevalence as the main outcome in our study, our results can also be regarded robust against potential seasonal variations of MPH intake (e. g. treatment interruptions during summer breaks). Since cross-sectional analyses have shown regional variations in ADHD prevalence in Germany for different years $[19,20]$, the consideration of regional heterogeneity in the standardisation of ADHD prevalence rates is a further strength of our study. Despite unchanged regional age-specific rates, regionally varying development of the age distribution alone could result in changes in the nationwide age-specific prevalence rates. To compensate, we stratified the crude prevalence rates and the population used in the standardisation method also by federal state. Further, we identified treatment in a follow-up period of one year for each ADHD case starting with its index diagnosis and did not restrict the analysis to prescriptions and procedures exclusively from the calendar year under study.

However, some limitations should be mentioned. Due to the nature of our data source, our results can only be regarded as administrative prevalences, not including ADHD cases with subthreshold symptomatology or without contact to the medical sector. Similarly, information on interventions other than drug treatment and behaviour therapy (e.g. occupational therapy) as well as on nonreimbursable therapeutic procedures is not included in GePaRD. Temporal variations in the usage of 
this therapy option may have also influenced the proportion of ADHD cases treated with medications or psychotherapy. However, we assume this influence was small as occupational therapy is intended to accompany drug treatment, not to replace it. It is also possible, that qualitative changes in the diagnostics of ADHD (e.g. new screenings, increased awareness of ADHD among treating physicians) could have influenced ADHD prevalence. As such changes are also not visible in GePaRD, we cannot estimate whether this might have biased our results. A recent review [31] has shown no change in the worldwide population-based prevalence of ADHD in the past 30 years and it has been suggested that changes in the prevalence based on administrative or claims data result from improved diagnostics or increased functional impairment [37]. Despite stable disease prevalence, however, an increase in diagnosed ADHD prevalence and therefore an increase in the number of ADHD cases treated by physicians would also increase the population potentially treated with ADHD drugs. Further, ADHD prevalence rates based on ICD-10-GM criteria are lower than those based on DSM criteria $[38,39]$ and compared to "ADHD" according to DSM-IV, the "hyperkinetic disorder" according to ICD-10 can generally be seen as a more severe subtype [1]. In the past, German guidelines have favoured diagnosing according to DSM-IV although coding of ADHD occurs in ICD-10-GM. This change could have, at least partly, triggered the ADHD prevalence increase found in this study. The dispensation of stimulants in Germany requires a prescription by a physician. Although people may choose to pay out of pocket for these stimulants it seems very unlikely that this would happen for children and adolescents as stimulants are fully covered by SHIs for this age group. Therefore, we believe that stimulant therapy of insured children and adolescents is almost fully documented in the claims data. However, as it applies also to other pharmacoepidemiological databases, we could not assess whether the dispensed drug amounts were actually taken by the individuals. Overall, the trends and developments of MPH prescriptions as described in our cross-sectional analyses could be substantially enriched by further longitudinal analyses of incidence rates across time. Such analyses were not planned for and covered by funding of the underlying study as they were beyond the scope of its initial objectives. Thus, further studies could contribute to our findings by considering 
longitudinal investigations of MPH prescriptions across longer periods of time. Further, the low rates of psychotherapy in our study should be interpreted very cautiously, especially in lights of international guidelines that actually recommend non-medical interventions over pharmacological treatments, particularly in the very young. Thus we have deliberately chosen a very narrow operationalisation, which depicted psychotherapy in terms of long-term cognitive behavioural therapy but this might have resulted in an underestimation of the number of actually treated children. Otherwise, Gellad et al. [40] found in a US study in 2010 among 0-17 years old children treated with ADHD medication a median county-level proportion of $7.1 \%$ receiving at least 8 visits of concurrent psychotherapy which is similar to our results based on reimbursed psychotherapeutic sessions typically including 25 visits. Based on our data, the calculation of corresponding percentages reveals increasing annual proportions of $5.6 \%$ to $7.1 \%$ for the years $2010-2013$.

In summary, between 2004 and 2008, the increase of the total amount of prescribed and dispensed MPH drugs in Germany can be explained by the increasing ADHD prevalence and the concurrent increasing mean amount of DDDs prescribed per case. In contrast, the small increase of the total amount of dispensed MPH drugs after 2008 could mainly be based on the fact that increases in ADHD prevalence were counteracted by decreasing proportions of drug-treated ADHD cases and slightly decreasing mean amounts of DDDs prescribed per drug-treated case. Finally, it is important that our analyses do not allow any inferences about potential benefits or hazards that might come along with the prescription trends as presented. Our figures should rather be taken as a helpful groundwork for further studies investigating such effects, since the mode of action of MPH treatment is not fully understood and the long-term effects and safety of ADHD treatments are still understudied. Considering the facts that MPH is often combined with other medication that might warrant special caution, such as antipsychotics [41, 42], and that such outcomes might be dose-related, it is important to clarify whether an overall increase of prescriptions is rather due to an increase of cases, increase of dosage per case or a combination of both, in order to estimate potential future risks. 


\section{Ethical standard statement}

In Germany, the utilization of health insurance data for scientific research is regulated by the Code of Social Law. All involved health insurance providers as well as the German Federal (Social) Insurance Office and the Senator for Science, Health, and Consumer Protection in Bremen as their responsible authorities approved the use of GePaRD data for this study. Informed consent for studies based on GePaRD is not required by law and according to the Ethics Committee of the University of Bremen these studies are exempt from institutional review board review.

\section{Data accessibility statement}

In accordance with German data protection regulations, access to the data of the German Pharmacoepidemiological Database must not be given to third parties. Furthermore, as we are not the owners of the data we are not legally entitled to grant access to the data.

\section{References}

1. Bachmann CJ, Wijlaars LP, Kalverdijk LJ, et al. Trends in ADHD medication use in children and adolescents in five western countries, 2005-2012. Eur Neuropsychopharmacol 2017;27:484-493.

2. Bruckner TA, Hodgson A, Mahoney CB, et al. Health care supply and county-level variation in attention-deficit hyperactivity disorder prescription medications. Pharmacoepidemiol Drug Saf 2012;21:442-449.

3. Dalsgaard S, Nielsen HS, Simonsen M. Five-fold increase in national prevalence rates of attentiondeficit/hyperactivity disorder medications for children and adolescents with autism spectrum disorder, attention-deficit/hyperactivity disorder, and other psychiatric disorders: a Danish register-based study. J Child Adolesc Psychopharmacol 2013;23:432-439. 
4. Hartz I, Skurtveit S, Steffenak AK, et al. Psychotropic drug use among 0-17 year olds during 20042014: a nationwide prescription database study. BMC Psychiatry 2016;16:12.

5. Ilyas S, Moncrieff J. Trends in prescriptions and costs of drugs for mental disorders in England, 1998-2010. Br J Psychiatry 2012;200:393-398.

6. Morkem R, Patten S, Queenan J, et al. Recent Trends in the Prescribing of ADHD Medications in Canadian Primary Care. J Atten Disord 2017; doi.org/10.1177/1087054717720719 [Epub ahead of print].

7. Steinhausen HC, Bisgaard C. Nationwide time trends in dispensed prescriptions of psychotropic medication for children and adolescents in Denmark. Acta Psychiatr Scand 2014;129:221-231.

8. Lohse MJ, Müller-Oerlinghausen B. Psychopharmaka. In: Schwabe U, Paffrath D (ed) Arzneiverordnungs-Report 2014: Aktuelle Daten, Kosten, Trends und Kommentare [Drug prescription report 2014: current data, costs, trends and comments]. Springer, Berlin, Heidelberg, 2014;pp 921-965.

9. German Federal Statistical Office. Fortschreibung des Bevölkerungsstandes [Recording of the population]. GENESIS-Online Datenbank, 2017. Available at: https://wwwgenesis.destatis.de/genesis/online/link/tabellen/12411*. Accessed August 17, 2018.

10. Winterstein AG. ADHD treatment--supply or demand? Pharmacoepidemiol Drug Saf 2012;21:450451.

11. Lindemann C, Langner I, Kraut AA, et al. Age-specific prevalence, incidence of new diagnoses, and drug treatment of attention-deficit/hyperactivity disorder in Germany. J Child Adolesc Psychopharmacol 2012;22:307-314.

12. Bachmann CJ, Philipsen A, Hoffmann F. ADHD in Germany: Trends in Diagnosis and Pharmacotherapy. Dtsch Arztebl Int 2017;114:141-148.

13. Garbe E, Mikolajczyk RT, Banaschewski T, et al. Drug treatment patterns of attentiondeficit/hyperactivity disorder in children and adolescents in Germany: results from a large population-based cohort study. J Child Adolesc Psychopharmacol 2012;22:452-458. 
14. OhImeier C, Langner I, Hillebrand K, et al. Mortality in the German Pharmacoepidemiological Research Database (GePaRD) compared to national data in Germany: results from a validation study. BMC Public Health 2015;15:570.

15. Pigeot I, Ahrens W. Establishment of a pharmacoepidemiological database in Germany: methodological potential, scientific value and practical limitations. Pharmacoepidemiol Drug Saf 2008;17:215-223.

16. Knopf $H$, Holling $H$, Huss $M$, et al. Prevalence, determinants and spectrum of attention-deficit hyperactivity disorder (ADHD) medication of children and adolescents in Germany: results of the German Health Interview and Examination Survey (KiGGS). BMJ Open 2012;2:e000477.

17. Fay MP, Feuer EJ. Confidence intervals for directly standardized rates: a method based on the gamma distribution. Stat Med 1997;16:791-801.

18. German Federal Statistical Office. Lebendgeborene und Veränderung zum Vorjahr [Live births and change to the previous year]. GENESIS-Online Datenbank, 2017. Available at: https://www.destatis.de/DE/ZahlenFakten/GesellschaftStaat/Bevoelkerung/Geburten/Tabellen/ LebendgeboreneDifferenz.html;jsessionid=7AB07B64DB365D37B67DF0ACD91F0AE7.InternetLiv e1. Accessed August 17, 2018.

19. Grobe TG, Bitzer EM, Schwartz FW. BARMER GEK Arztreport: Schwerpunkt Aufmerksamkeitsdefizit-/Hyperaktivitätsstörungen [BARMER GEK physician report: focus attention-deficit/hyperactivity disorder]. Asgard-Verlagsservice, Siegburg, 2013.

20. Roick C, Waltersbacher A. Administrative Prävalenz und medikamentöse Behandlung hyperkinetischer Störungen bei Kindern und Jugendlichen in Deutschland 2006 bis 2013 [Administrative prevalence and drug treatment of hyperkinetic disorders in children and adolescents in Germany in the years 2006 to 2013]. In: Klauber J, Günster C, Gerste B, Robra BP, Schmacke N (ed) Versorgungs-Report 2015/2016. Schwerpunkt: Kinder und Jugendliche.Schattauer GmbH, Verlag für Medizin und Naturwissenschaften, Stuttgart, 2015;pp 137-166. 
21. Olfson M, Druss BG, Marcus SC. Trends in Mental Health Care among Children and Adolescents. N Engl J Med 2015;373:2029-2038.

22. Safer DJ, Rajakannan T, Burcu M, et al. Trends in subthreshold psychiatric diagnoses for youth in community treatment. JAMA Psychiatry 2015;72:75-83.

23. Abbas S, Ihle P, Adler JB, Engel S, Günster C, Linder R, Lehmkuhl G, Schubert I.

Psychopharmacological Prescriptions in Children and Adolescents in Germany. Dtsch Arztebl Int 2016;113:396-403.

24. Gemeinsamer Bundesausschuss (G-BA). Zum Schutz von Kindern und Jugendlichen - Verordnung von Stimulantien nur in bestimmten Ausnahmefällen [For the safety of children and adolescents - prescription of stimulants only in certain exceptional cases]. Press release No. 27, September 16, 2010. Available at: https://www.g-ba.de/institution/presse/pressemitteilungen/351/. Accessed August 17, 2018.

25. Gemeinsamer Bundesausschuss (G-BA). Arzneimittelrichtlinie - Anlage III: Stand Übersicht über Verordnungseinschränkungen und -ausschlüsse in der Arzneimittelversorgung durch die Arzneimittel-Richtlinie und aufgrund anderer Vorschriften (§ 34 Absatz 1 Satz 6 und Absatz 3 SGB V), Hinweise zur wirtschaftlichen Verordnungsweise von nicht verschreibungspflichtigen Arzneimitteln für Kinder bis zum vollendeten 12. Lebensjahr und für Jugendliche mit Entwicklungsstörungen bis zum vollendeten 18.Lebensjahr sowie Verordnungseinschränkungen und -ausschlüsse von sonstigen Produkten. Oktober 25, 2016. Available at: https://www.gba.de/downloads/83-691-430/AM-RL-III_Verordnungeinschraenkungen_2016-10-25.pdf. Accessed August 17, 2018.

26. Zetterqvist J, Asherson P, Halldner L, et al. Stimulant and non-stimulant attention deficithyperactivity disorder drug use: total population study of trends and discontinuation patterns 2006-2009. Acta Psychiatr Scand 2013;128:70-77.

27. Zuvekas SH, Vitiello B. Stimulant Medication Use among U.S. Children: A Twelve-Year Perspective. Am J Psychiatry 2012;169:160-166. 
28. Martinez DPS, Perez JJG. The epidemiology of pharmacologically treated attention deficit hyperactivity disorder (ADHD) in the Region of Murcia, Spain: Differences by gender, age and location of residence. An Pediatr (Barc) 2018;88:138-190.

29. McCarthy S, Wilton L, Murray ML, et al. (2012). The epidemiology of pharmacologically treated attention deficit hyperactivity disorder (ADHD) in children, adolescents and adults in UK primary care. BMC Pediatr 2012;12:78.

30. Wang L, Lee, SY, Yuan SS, et al. Prevalence rates of youths diagnosed with and medicated for ADHD in a nationwide survey in Taiwan from 2000 to 2011. Epidemiol Psychatr Sci 2017;26:624634.

31. Polanczyk GV, Willcutt EG, Salum GA, et al. ADHD prevalence estimates across three decades: an updated systematic review and meta-regression analysis. Int J Epidemiol 2014;43:434-442.

32. Beau-Lejdstrom R, Douglas I, Evans SJ, et al. Latest trends in ADHD drug prescribing patterns in children in the UK: prevalence, incidence and persistence. BMJ Open 2016;6:e010508.

33. Committee for Medicinal Products for Human Use. Elements recommended for inclusion in Summaries of Product Characteristics for methylphenidate-containing medicinal products authorised for the treatment of ADHD in children aged six years and above and adolescents. European Medicines Agency. January 22, 2009. Available at: http://www.ema.europa.eu/docs/en_GB/document_library/Referrals_document/Methylphenid ate_31/WC500011184.pdf. Accessed August 17, 2018.

34. Elia J, Vetter VL. Cardiovascular effects of medications for the treatment of attention-deficit hyperactivity disorder: what is known and how should it influence prescribing in children? Paediatr Drugs 2010;12:165-75.

35. Schink T, Garbe E. Assessment of the representativity of in-patient hospital diagnoses in the German Pharmacoepidemiological Research Database. Abstracts of the 26th International Conference on Pharmacoepidemiology \& Therapeutic Risk Management, 19-22 August 2010, Brighton, UK. Pharmacoepidemiol Drug Saf 2010 ;19:S178-179. 
36. Schink T, Garbe E. Representativity of dispensations of non-steroidal anti-inflammatory drugs (NSAIDs) in the German Pharmacoepidemiological Research Database. Abstracts of the 26th International Conference on Pharmacoepidemiology \& Therapeutic Risk Management, 19-22 August 2010, Brighton, UK. Pharmacoepidemiol Drug Saf 2010 ;19:S294.

37. Banaschewski T, Becke, K, Döpfner M, et al. Attention-Deficit/Hyperactivity Disorder. Dtsch Arztebl Int 2017;114:149-159.

38. Döpfner M, Breuer D, Wille N, et al. How often do children meet ICD-10/DSM-IV criteria of attention deficit-/hyperactivity disorder and hyperkinetic disorder? Parent-based prevalence rates in a national sample--results of the BELLA study. Eur Child Adolesc Psychiatry 2008;17(Suppl 1):59-70.

39. Polanczyk G, de Lima MS, Horta BL, et al. The worldwide prevalence of ADHD: a systematic review and metaregression analysis. Am J Psychiatry 2007;164:942-948.

40. Gellad WF, Stein BD, Ruder T, et al. Geographic variation in receipt of psychotherapy in children receiving attention-deficit/hyperactivity disorder medications. JAMA Pediatr 2014;168:10741076.

41. Scholle O, Banaschewski T, Enders D, et al. Use and Characteristics of Antipsychotic/Methylphenidate Combination Therapy in Children and Adolescents with a Diagnosis of Attention-Deficit/Hyperactivity Disorder. J Child Adolesc Psychopharmacol 2018;28:415-422.

42. Hauck TS, Lau C, Wing LLF, et al. ADHD Treatment in Primary Care: Demographic Factors, Medication Trends, and Treatment Predictors. Can J Psychiatry 2017;62:393-402 


\section{Figure Captions}

FIGURE 1. Administrative 1-year period prevalence of ADHD for 3- to 17-year-old children and adolescents in Germany standardised for age and federal state for the years 2004 to 2013, overall and by sex (vertical bars indicate 95\% CI) (corresponding values are listed in Supplemental Digital Content_5)

FIGURE 2. Age-standardised proportions of ADHD cases treated with methylphenidate or atomoxetine for the years 2004 to 2013 , overall and by sex (vertical bars indicate $95 \% \mathrm{Cl}$ ) (corresponding values are listed in Supplemental Digital Content_5)

FIGURE 3. Age-standardised proportions of ADHD cases with psychotherapeutic treatment only or with both psychotherapy and drug treatment (methylphenidate or atomoxetine) within one year after case diagnosis by sex and calendar year (vertical bars indicate $95 \% \mathrm{Cl}$ ) (corresponding values are listed in Supplemental Digital Content_5)

FIGURE 4. Age-standardised mean cumulative Defined Daily Doses (DDDs) prescribed within one year after case diagnosis per drug-treated ADHD case for the age group 5 to 17 years stratified by drug ( $\mathrm{MPH}=$ methylphenidate, $\mathrm{ATX}=$ atomoxetine), sex and calendar year (vertical bars indicate $95 \% \mathrm{Cl}$ )

${ }^{\text {a }}$ children's DDDs for MPH and adult DDDs for ATX 
List of Files with Supplemental Digital Content

Supplemental Digital Content_1.pdf

Supplemental Digital Content_2.pdf

Supplemental Digital Content_3.pdf

Supplemental Digital Content_4.pdf

Supplemental Digital Content_5.pdf

Supplemental Digital Content_6.pdf

Supplemental Digital Content_7.pdf
(Table)

(Text)

(Text)

(Table)

(Table)

(Figure)

(Figure) 


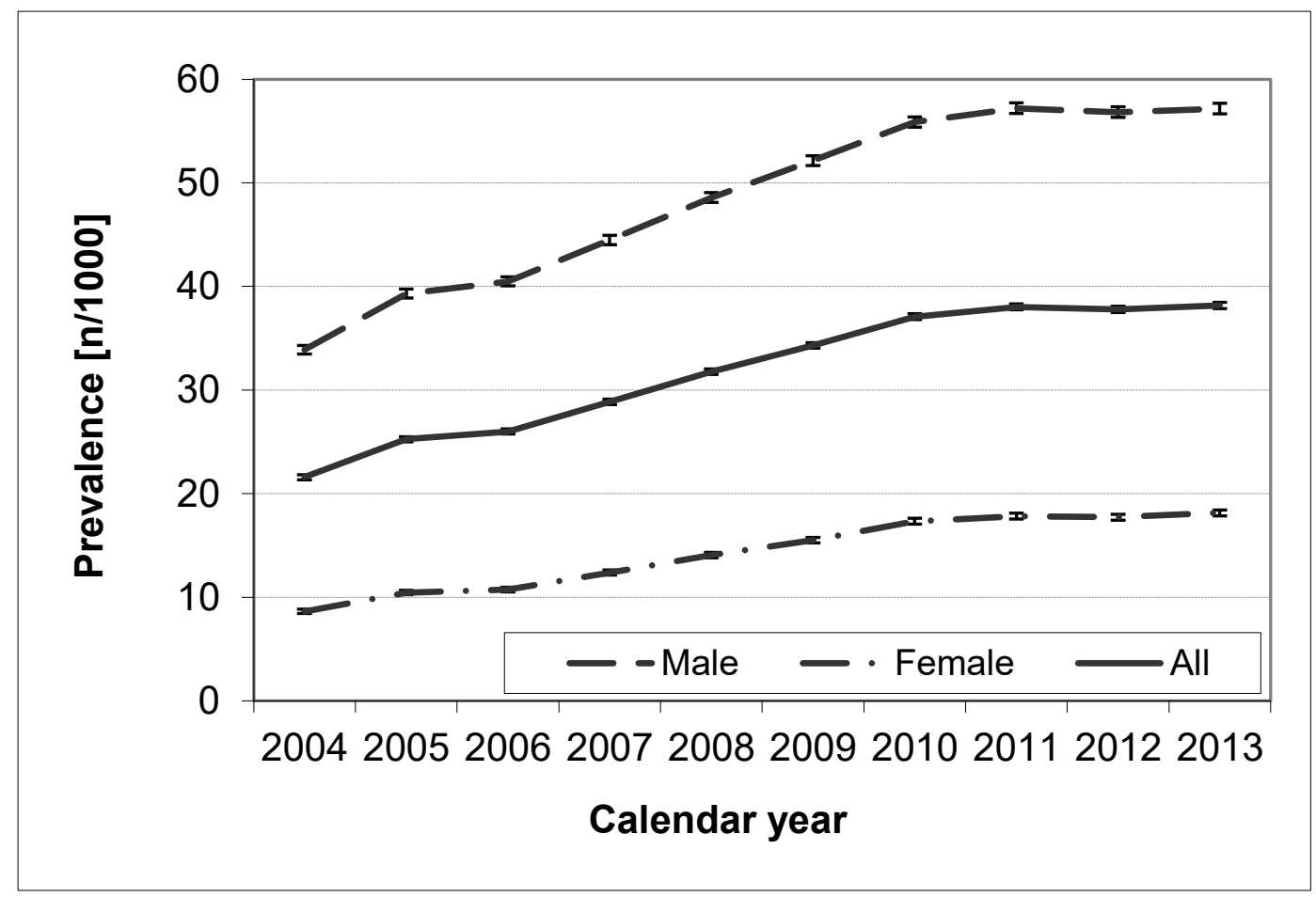




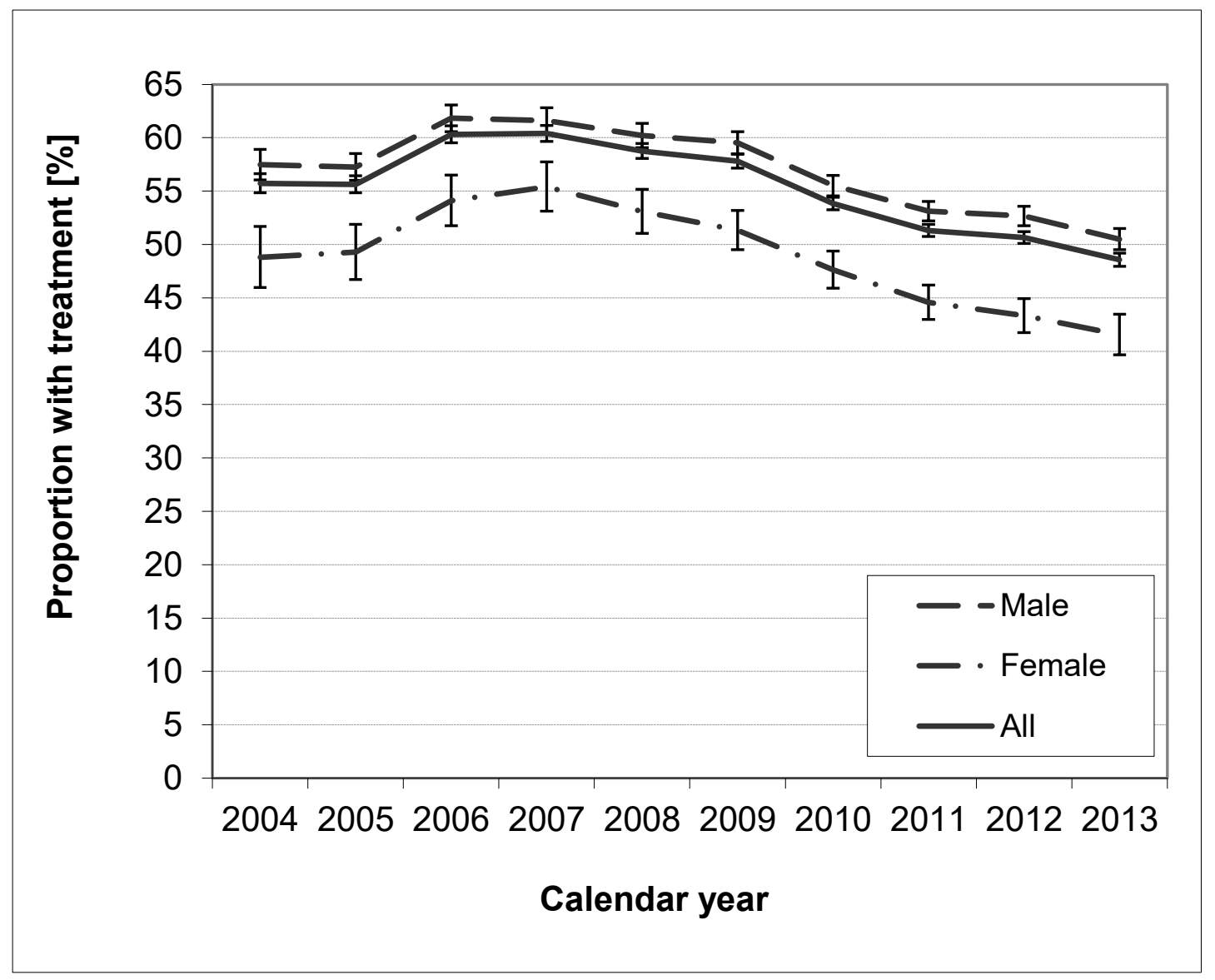




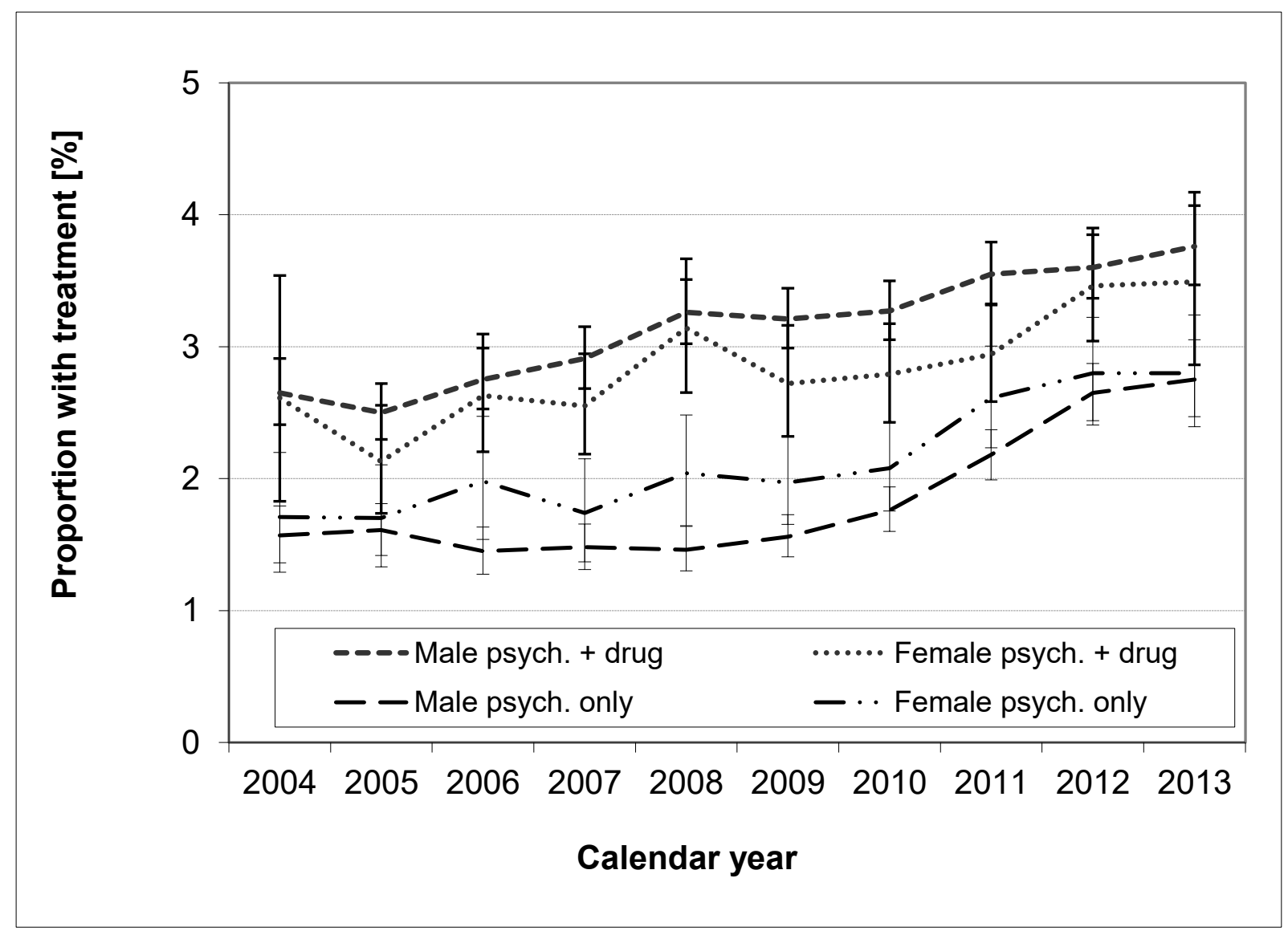




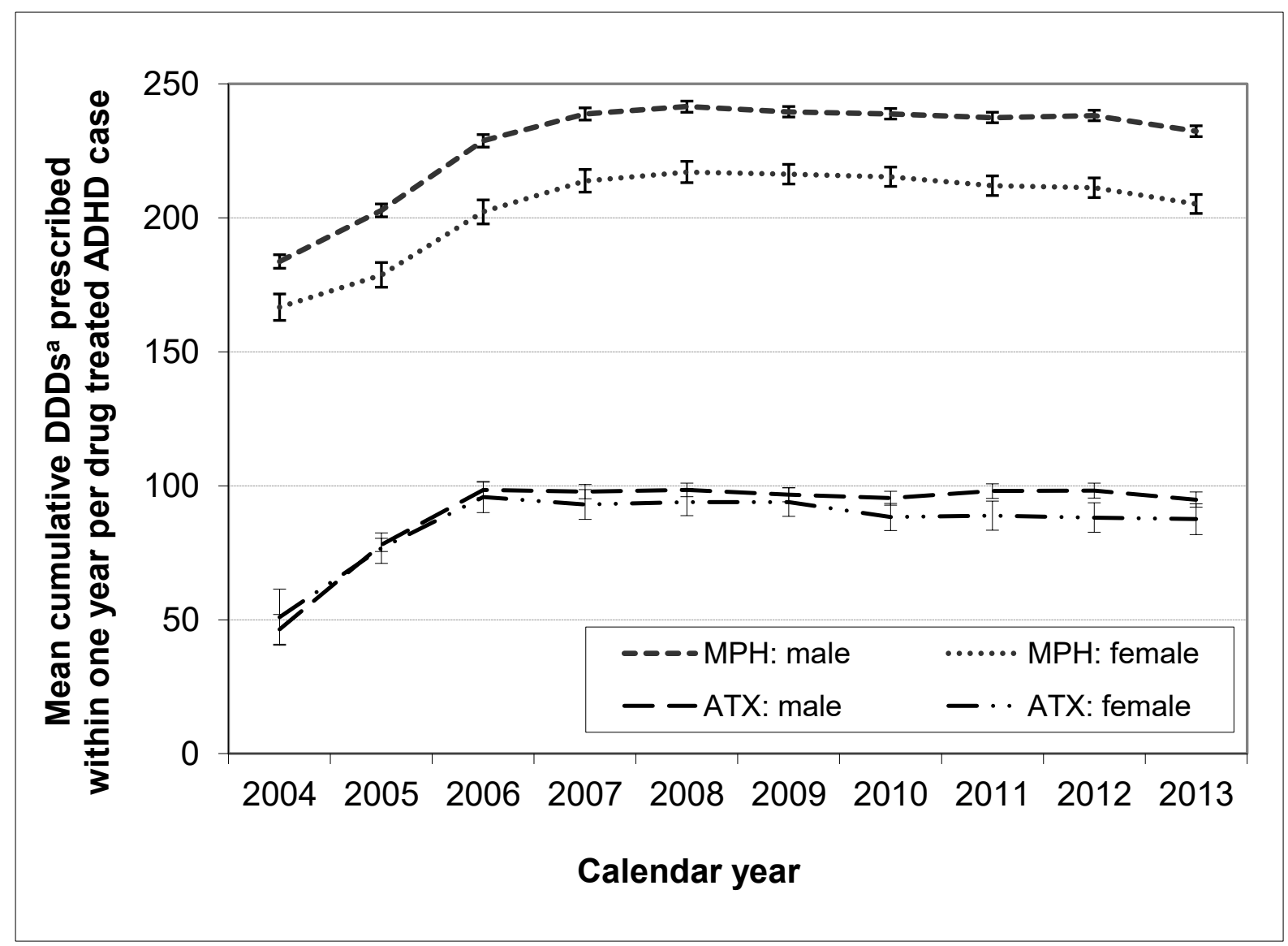


Supplemental Digital Content 1. Fee schedule items considered for the identification of outpatient behaviour psychotherapy

\begin{tabular}{llll}
\hline Code & $\begin{array}{l}\text { Validity period } \\
\text { within study period }\end{array}$ & $\begin{array}{l}\text { Type of behaviour } \\
\text { therapy }\end{array}$ & $\begin{array}{l}\text { Number of sessions (each of at } \\
\text { least } 50 \text { minutes duration) }\end{array}$ \\
\hline 0881 & $2004-2005$ & Short-term, individual & Up to 25 sessions \\
0882 & $2004-2005$ & Long-term, individual & More than 25 sessions \\
0883 & $2004-2005$ & Short-term, group & Up to 25 sessions \\
0884 & $2004-2005$ & Long-term, group & More than 25 sessions \\
35220 & $2005-2013$ & Short-term, individual & Up to 25 sessions \\
35221 & $2005-2013$ & Long-term, individual & More than 25 sessions \\
35222 & $2005-2013$ & Short-term, group & Up to 25 sessions \\
35223 & $2005-2013$ & Long-term, group & More than 25 sessions \\
\hline
\end{tabular}




\section{Supplemental Digital Content 2. Calculation of standardised prevalence rates}

First, claims data-based crude ADHD 1-year period prevalence rates were calculated stratified by sex, age (one-year age classes), federal state and calendar year. Subjects were included as cases for the numerator of the prevalence rate if their records showed any index date which met the ADHD definition in the respective year. The denominator included all persons who were at least continuously insured from July 1 of the respective year until June 30 of the following year. This correlates with the so-called 'midyear population' but was restricted to those subjects which had a continuous insurance period of at least one year. This length corresponds to the insurance period that was necessary in order to be identified as an ADHD case via the case algorithm (for details see section 'Study population and identification of ADHD cases'). Second, based on the crude 1-year period prevalence rates, we calculated standardised annual prevalence rates using the German population figures of 2006 derived from the Federal Statistical Office: sex-specific rates were standardised for age (one-year age classes) and federal state and overall rates additionally for sex. Let $z$ enumerate the 10 calendar years of the study period $(z=1, \ldots, 10)$, let $k$ differentiate sex $(k=1,2)$, let $j$ distinguish the 16 federal states of Germany $(j=1, \ldots, 16)$, let $i$ enumerate the 15 one-year age classes from age 3 to age $17(i=1, \ldots, 15)$, let $n$ be the population counts of Germany from 2006 and let CPR be the crude prevalence rates, then annual sex-specific standardised prevalence rates $S T P R_{z k}$ were calculated by

$$
S T P R_{z k}=\frac{\sum_{j=1}^{16} \sum_{i=1}^{15} C P R_{z k j i} n_{k j i}}{\sum_{j=1}^{16} \sum_{i=1}^{15} n_{k j i}}
$$

Total standardised prevalence rates were calculated in the same way by additionally aggregating the figures on the level of sex. 
Supplemental Digital Content 3. Calculation of the mean amount of prescribed DDDs per ADHD case and corresponding 95\% confidence intervals

For MPH and based on the individual cumulative DDDs prescribed within one year for all ADHD cases with MPH treatment, we estimated the mean amount of DDDs among MPHtreated ADHD cases stratified by sex and age (one-year age classes). As case numbers for the age groups 3 and 4 years were very low, these age groups were excluded from the calculation. Further, the age-weighted mean amount of MPH DDDs for the total age group of 5- to 17-year-old children and adolescents was calculated for each calendar year stratified by sex. Let $\mu_{j i}$ be the mean amount of DDDs for a single age group $i\{1, \ldots, 13\}$ in calendar year $j$, let $\sigma_{j i}$ be the corresponding standard error of the mean, let $\omega_{i}$ be the age-specific weight and let $z_{0.975}$ be the $97.5 \%$ quantile of the standard normal distribution, then the age-weighted mean $\mu_{j}$ and corresponding limits $C L_{j}$ for $95 \% \mathrm{Cl}$ were calculated using

$$
\begin{aligned}
& \mu_{j}=\sum_{i=1}^{13} \omega_{i} \mu_{j i} \\
& C L_{j}=\mu_{j} \pm z_{0.975} \bullet \sqrt{\sum_{i=1}^{13} \omega_{i}^{2} \sigma_{j i}^{2}}
\end{aligned}
$$

In the same way, amounts for mean cumulative ATX DDDs per ATX-treated ADHD case were calculated. 
Supplemental Digital Content 4. Descriptive figures $[N]$ for the annual total study populations of 3- to 17-year-old children in GePaRD stratified by sex and calendar year

\begin{tabular}{|c|c|c|c|c|c|}
\hline Sex & $\begin{array}{c}\text { Calendar } \\
\text { year }\end{array}$ & $\begin{array}{c}\text { Study } \\
\text { population }\end{array}$ & $\begin{array}{l}\text { Prevalent } \\
\text { ADHD cases }\end{array}$ & $\begin{array}{l}\text { Drug-treated } \\
\text { ADHD cases }\end{array}$ & $\begin{array}{l}\text { ADHD cases with } \\
\text { psychotherapy }\end{array}$ \\
\hline \multirow[t]{10}{*}{ Boys } & 2004 & 801628 & 26930 & 15708 & 1357 \\
\hline & 2005 & 879211 & 34660 & 20030 & 1680 \\
\hline & 2006 & 878672 & 35908 & 23265 & 1818 \\
\hline & 2007 & 885638 & 40157 & 26421 & 2082 \\
\hline & 2008 & 882715 & 44084 & 28769 & 2376 \\
\hline & 2009 & 917690 & 49103 & 32047 & 2711 \\
\hline & 2010 & 932750 & 53237 & 32878 & 3016 \\
\hline & 2011 & 933579 & 54101 & 32927 & 3284 \\
\hline & 2012 & 943020 & 53677 & 32506 & 3399 \\
\hline & 2013 & 949602 & 53904 & 31842 & 3325 \\
\hline \multirow[t]{10}{*}{ Girls } & 2004 & 763049 & 6608 & 3271 & 291 \\
\hline & 2005 & 838556 & 8867 & 4405 & 401 \\
\hline & 2006 & 837112 & 9139 & 5354 & 480 \\
\hline & 2007 & 843412 & 10706 & 6343 & 561 \\
\hline & 2008 & 839664 & 12181 & 7049 & 637 \\
\hline & 2009 & 872561 & 13916 & 8023 & 722 \\
\hline & 2010 & 886331 & 15599 & 8473 & 854 \\
\hline & 2011 & 887637 & 15928 & 8490 & 975 \\
\hline & 2012 & 896009 & 15865 & 8311 & 1045 \\
\hline & 2013 & 902454 & 16181 & 8140 & 1047 \\
\hline \multirow[t]{10}{*}{ All } & 2004 & 1564677 & 33538 & 18979 & 1648 \\
\hline & 2005 & 1717767 & 43527 & 24435 & 2081 \\
\hline & 2006 & 1715784 & 45047 & 28619 & 2298 \\
\hline & 2007 & 1729050 & 50863 & 32764 & 2643 \\
\hline & 2008 & 1722379 & 56265 & 35818 & 3013 \\
\hline & 2009 & 1790251 & 63019 & 40070 & 3433 \\
\hline & 2010 & 1819081 & 68836 & 41351 & 3870 \\
\hline & 2011 & 1821216 & 70029 & 41417 & 4259 \\
\hline & 2012 & 1839029 & 69542 & 40817 & 4444 \\
\hline & 2013 & 1852056 & 70085 & 39982 & 4372 \\
\hline
\end{tabular}


Supplemental Digital Content 5. Annual age standardized estimates and $95 \%$ confidence intervals for ADHD prevalence, for the proportion of ADHD cases treated with ADHD drugs only, for the proportion of ADHD cases treated with psychotherapy only, and for the proportion of ADHD cases treated with ADHD drugs and psychotherapy (values are presented graphically in Fig. 1-3 in the corresponding article)

\begin{tabular}{|c|c|c|c|c|c|}
\hline \multirow[b]{2}{*}{ Sex } & \multirow[b]{2}{*}{ Year } & \multicolumn{4}{|c|}{ Age adjusted estimates ( $95 \%$ confidence interval) for } \\
\hline & & $\begin{array}{c}\text { ADHD prevalence } \\
{\left[\mathrm{n} / 10^{3}\right]}\end{array}$ & $\begin{array}{l}\text { Proportion of ADHD } \\
\text { cases with drug } \\
\text { treatment only [\%] }\end{array}$ & $\begin{array}{c}\text { Proportion of } \\
\text { ADHD cases with } \\
\text { psychotherapy } \\
\text { only [\%] }\end{array}$ & $\begin{array}{l}\text { Proportion of ADHD } \\
\text { cases with drug } \\
\text { treatment and } \\
\text { psychotherapy [\%] }\end{array}$ \\
\hline Male & 2004 & $33.88(33.47-34.30)$ & $57.46(56.04-58.89)$ & $1.57(1.36-1.79)$ & 2.65 ( $2.41-2.91)$ \\
\hline Male & 2005 & $39.31(38.89-39.74)$ & $57.25(56.01-58.50)$ & $1.61(1.42-1.81)$ & $2.50(2.30-2.72)$ \\
\hline Male & 2006 & $40.47(40.04-40.90)$ & $61.82(60.57-63.08)$ & $1.45(1.27-1.63)$ & 2.75 ( $2.53-2.99)$ \\
\hline Male & 2007 & $44.48(44.03-44.93)$ & $61.61(60.43-62.80)$ & $1.48(1.31-1.66)$ & $2.91(2.68-3.15)$ \\
\hline Male & 2008 & $48.57(48.10-49.04)$ & $60.20(59.08-61.33)$ & $1.46(1.30-1.64)$ & $3.26(3.02-3.51)$ \\
\hline Male & 2009 & $52.14(51.66-52.62)$ & $59.51(58.47-60.56)$ & $1.56(1.41-1.73)$ & $3.21(2.99-3.44)$ \\
\hline Male & 2010 & $55.84(55.35-56.34)$ & $55.51(54.55-56.48)$ & $1.76(1.60-1.94)$ & $3.27(3.05-3.50)$ \\
\hline Male & 2011 & $57.19(56.69-57.70)$ & $53.12(52.21-54.03)$ & 2.18 ( $1.99-2.37)$ & $3.55(3.32-3.79)$ \\
\hline Male & 2012 & $56.82(56.32-57.33)$ & $52.65(51.75-53.56)$ & 2.65 ( $2.44-2.87)$ & 3.60 ( $3.37-3.85)$ \\
\hline Male & 2013 & $57.16(56.66-57.66)$ & $50.50(49.51-51.50)$ & $2.75(2.47-3.05)$ & $3.76(3.47-4.07)$ \\
\hline Female & 2004 & $8.63(8.41-8.84)$ & $48.79(45.98-51.67)$ & $1.71(1.29-2.20)$ & $2.61(1.83-3.54)$ \\
\hline Female & 2005 & $10.45(10.23-10.68)$ & $49.27(46.73-51.88)$ & $1.70(1.33-2.10)$ & $2.13(1.74-2.56)$ \\
\hline Female & 2006 & $10.73(10.51-10.96)$ & $54.10(51.76-56.48)$ & $1.98(1.54-2.47)$ & $2.63(2.20-3.09)$ \\
\hline Female & 2007 & $12.38(12.14-12.62)$ & $55.40(53.11-57.74)$ & $1.74(1.37-2.15)$ & 2.55 ( 2.18- 2.95) \\
\hline Female & 2008 & $14.05(13.80-14.31)$ & $53.08(51.02-55.18)$ & $2.04(1.64-2.48)$ & 3.14 ( 2.65- 3.67) \\
\hline Female & 2009 & $15.50(15.24-15.78)$ & $51.33(49.52-53.18)$ & $1.97(1.65-2.32)$ & $2.72(2.32-3.16)$ \\
\hline Female & 2010 & $17.32(17.04-17.61)$ & $47.62(45.90-49.37)$ & $2.08(1.76-2.43)$ & $2.79(2.43-3.17)$ \\
\hline Female & 2011 & $17.83(17.54-18.12)$ & $44.57(42.97-46.20)$ & 2.61 ( $2.23-3.00)$ & $2.94(2.58-3.32)$ \\
\hline Female & 2012 & $17.72(17.44-18.01)$ & $43.33(41.76-44.93)$ & $2.80(2.41-3.22)$ & $3.46(3.04-3.90)$ \\
\hline Female & 2013 & $18.14(17.85-18.43)$ & $41.54(39.67-43.45)$ & $2.80(2.39-3.24)$ & 3.49 ( $2.86-4.17)$ \\
\hline All & 2004 & $21.58(21.34-21.82)$ & $55.74(54.49-56.99)$ & $1.60(1.41-1.80)$ & $2.61(2.38-2.85)$ \\
\hline All & 2005 & $25.25(25.01-25.50)$ & $55.62(54.52-56.73)$ & $1.62(1.45-1.81)$ & $2.45(2.26-2.64)$ \\
\hline All & 2006 & $25.99(25.74-26.23)$ & $60.36(59.26-61.48)$ & $1.54(1.38-1.71)$ & $2.74(2.54-2.95)$ \\
\hline All & 2007 & $28.84(28.59-29.10)$ & $60.42(59.37-61.47)$ & $1.53(1.38-1.69)$ & 2.84 ( $2.64-3.05)$ \\
\hline All & 2008 & $31.76(31.49-32.03)$ & $58.74(57.76-59.73)$ & $1.58(1.43-1.74)$ & $3.22(3.01-3.44)$ \\
\hline All & 2009 & $34.30(34.02-34.58)$ & $57.75(56.85-58.66)$ & $1.66(1.52-1.81)$ & $3.09(2.90-3.29)$ \\
\hline All & 2010 & $37.08(36.79-37.37)$ & $53.73(52.90-54.57)$ & 1.83 ( $1.69-1.99)$ & $3.17(2.98-3.36)$ \\
\hline All & 2011 & $38.02(37.73-38.31)$ & $51.22(50.43-52.01)$ & $2.28(2.11-2.46)$ & $3.43(3.23-3.63)$ \\
\hline All & 2012 & $37.78(37.48-38.07)$ & $50.50(49.72-51.28)$ & 2.70 ( $2.51-2.89)$ & 3.59 ( $3.38-3.80)$ \\
\hline All & 2013 & $38.15(37.86-38.45)$ & $48.46(47.59-49.33)$ & 2.79 ( 2.55-3.04) & $3.69(3.44-3.96)$ \\
\hline
\end{tabular}


a)

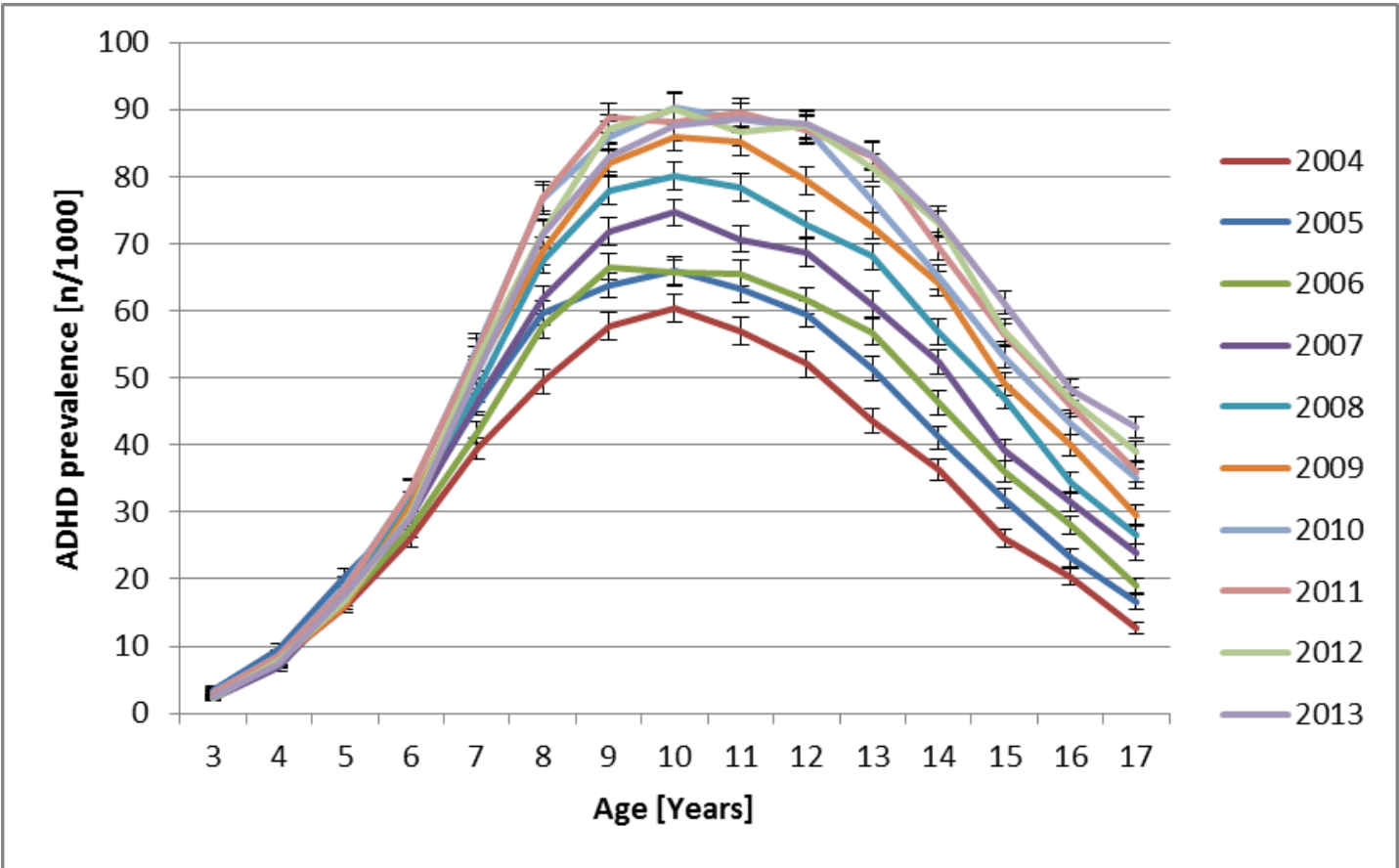

b)

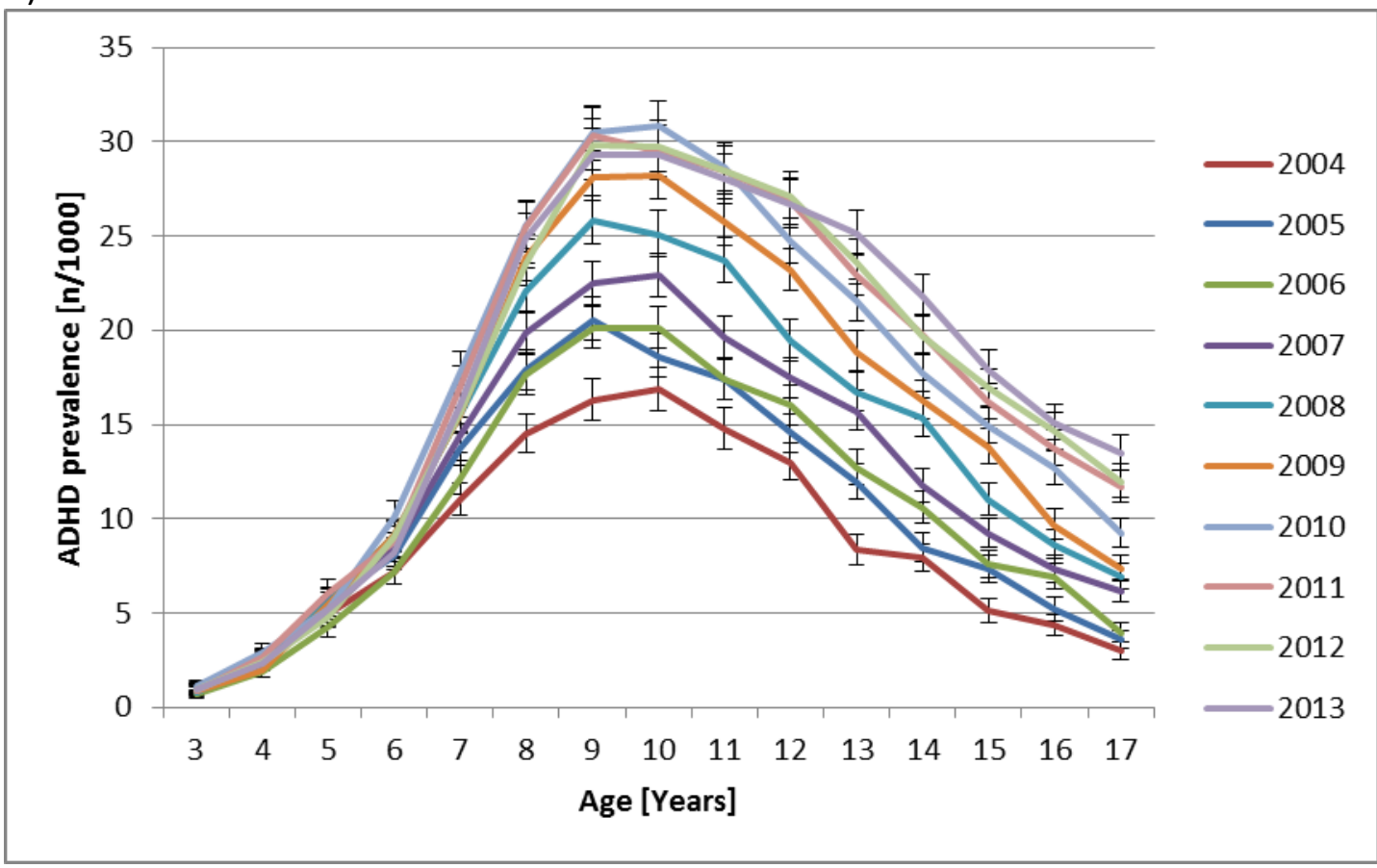

Supplemental Digital Content 6. Crude annual ADHD 1-year period prevalence and corresponding $95 \%$ confidence intervals (vertical bars) stratified by age and calendar year for children and adolescence: a) boys, b) girls 
a)

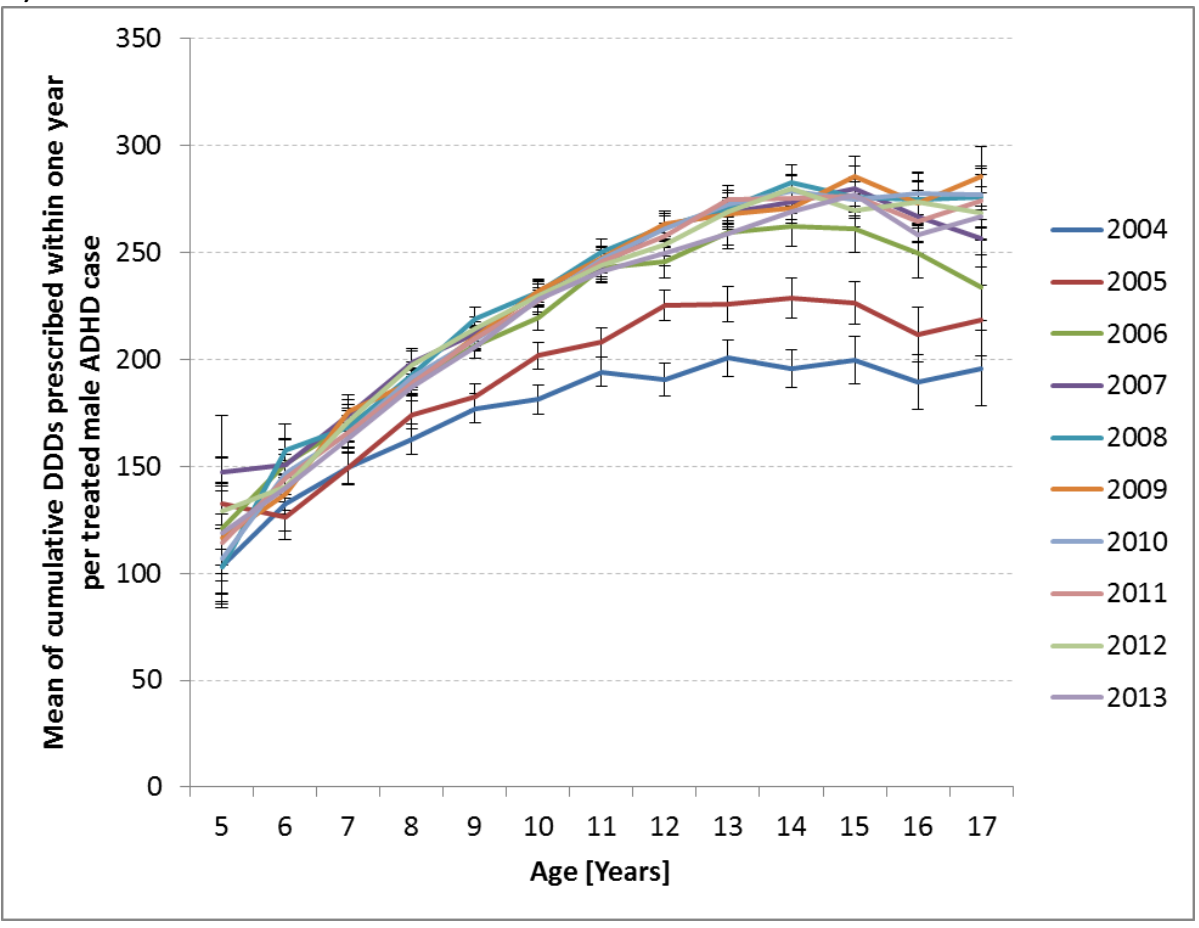

b)

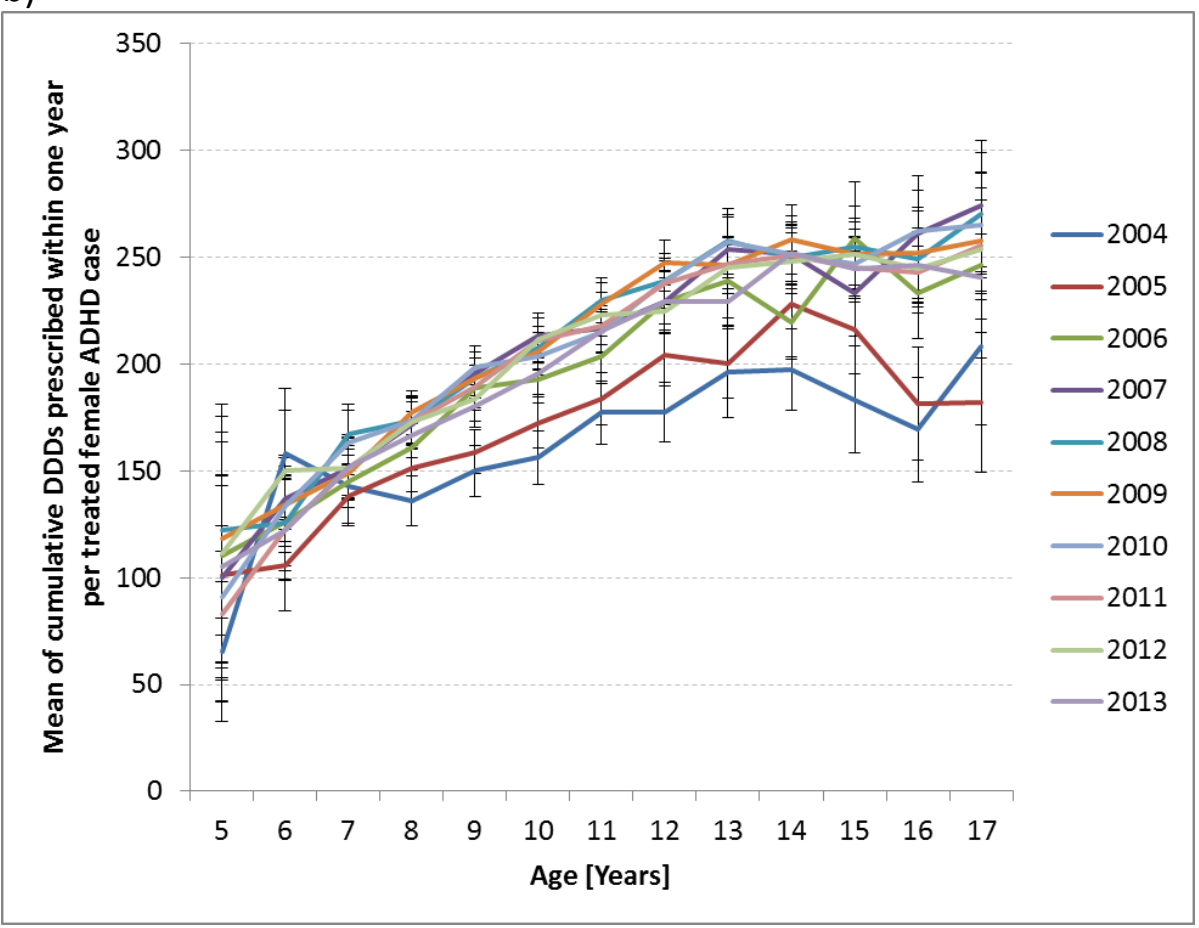

Supplemental Digital Content 7. Mean cumulative DDDs (=vertical axis; vertical bars indicate 95\% confidence intervals) of prescribed methylphenidate within one year per person stratified by age for different calendar years based on all ADHD cases treated at least once within one year after case index date: A) boys, B) girls (figures for the age groups of 3 and 4 years are not presented) 